\title{
Pendampingan Pembelajaran Bahasa Inggris bagi Murid melalui Metode Cerita Legend of Madura di Madrasah Tsanawiyah Miftahul Ulum Gunung Tangis Desa Rek-kerrek Kecamatan Palengaan
}

\author{
${ }^{1}$ Mosleh Habibullah, ${ }^{2}$ Achmad Baidawi, ${ }^{3}$ Fadilah, \\ ${ }^{4}$ Wahab Syakhirul Alim, ${ }^{5}$ Rabi'ah \\ Institut Agama Islam Negeri Madura \\ 1 moslehhabibullah@gmail.com, ${ }^{2}$ achmadbaidawi82@gmail.com, \\ dellatsalsi@gmail.com, ${ }^{4}$ wahab-alhabsy@iainmadura.ac.id, \\ 5robi'ah_43@yahoo.com
}

\begin{abstract}
Education plays a vital role in human civilization. It is not free of some problems. One of them is students, learning interest, especially in English learning. At the same time, English one of the skills in this digital era because English becomes an alternative language in global communication. Community service through English Learning Assistance for Students by Using Method of Telling Legend of Madura at Madrasah Tsanawiyah Miftahul Ulum Gunung Tangis Desa Rek-Kerrek Kecamatan Palengaan is aimed at help teacher and students solve the problems with various learning methods and media which present more exciting and enjoyable new atmosphere. From the result of assistance, it was found that students got much more interested and zealous to participate in learning proses. This community service is expected to be a model for teachers in designing more various learning activities to increase students' motivation and interest in learning the English language.
\end{abstract}

Keywords: Mentoring; Legend of Madura

\begin{abstract}
Abstrak
Pendidikan yang berperan sangat penting dalam peradaban manusia tidak terlepas dari berbagai permasalahan. Salah satunya minat belajar siswa yang kurang terutama dalam pembelajaran bahasa Inggris. Sedangkan bahasa Inggris merupakan salah satu keahlian bahasa yang harus dikuasai di era digital ini karena bahasa Inggris menjadi bahasa alternatif dalam komunikasi global. Pengabdian masyarakat melalui Pendampingan Pembelajaran Bahasa Inggris Bagi Murid Melalui Metode Cerita Legend of Madura di Madrasah Tsanawiyah Miftahul Ulum Gunung Tangis Desa Rekkerrek Kecamatan Palengaan bertujuan untuk membantu guru dan murid memberikan solusi atas permasalahan tersebut dengan variasi metode dan media pembelajaran yang manghadirkan suasana baru yang lebih menarik dan menyengangkan. Dari hasil pendampingan yang dilakukan ditemukan
\end{abstract}


bahwa siswa jauh lebih tertarik dan bersemangat dalam mengikuti proses pembelajaran. Kegiatan pengabdian ini diharapkan menjadi acuan bagi guru dalam merancang kegiatan pembelajarang yang lebih bervariasi sehingga bisa meningkatkan motivasi dan minta siswa dalam belajar bahasa Inggris.

Kata kunci: Pendampingan, Legend of Madura

\section{Pendahuluan}

Pendidikan merupakan sesuatu yang begitu essensia bagi kehidupan ummat manusia karena ia menjadi alat agar mampu menghadapi berbagai macam persoalan penting yang dihadapi manusia agar mampu mempertahankan keberlangsungan hidup mereka (Siregar, 2013: 18). Terdapat dua jenis pendidikan dilndonesia yaitu: 1) pendidikan formal, merupakan pendidikan yang memiliki jejang pendidikan yang sistematis dimulai dari pendidikan dasar, menengah, atas, dantinggi. 2) pendidikan nonformal, merupakan pendidikan yang berorientasi pada pengembangan potensi peserta didik dengan penekanan pada penguasaan pengetahuan dan keterampilan fungsional dan sikap serta kepribadian professional, 3) pendidikan informal merupakan pendidikan adalah jalur pendidikan berbasis keluarga dan lingkungan yang memiliki kegiatan belajar secara mandiri (Dariyo, 2004: 75).

Berbagai kompetensi dan keahlian perlu diajarkan dan dipraktekkan dalam proses pendidikan agar para generasi bisa bersaing secara global dan ikut serta dalam membangun bangsa ini. Salah satu keahlian yang perlu dikuasai yaitu kemampuan berbahasa asing terutama bahasa Inggris.

Bahasa Inggris merupakan bahasa universal karena ia dipergunakan oleh sebagian besar negara di dunia untuk berbagai keperluan di banyak sektor kehidupan (Maduwu, 2016). Selain menjadi bahasa Internasional, bahasa Inggris juga menjadi mata pelajaran wajib (Muatan Nasional) bagi siswa di Indonesia baik di tingkat Sekolah Menengah Pertama (SMP) ataupun Sekolah Menengah Atas (SMA) pada sistem pendidikan kita. Hal ini menjadi penting bagi siswa untuk mempelajari dan menguasai bahasa Inggris dalam dua konteks tersebut. Dalam konteks bahasa Inggris sebagai bahasa international, siswa perlu untuk menguasai bahasa Inggris agar mampu berkomunikasi dengan orang luar baik secara lisan maupun tulisan. Disamping itu, siswa juga penting untuk mempelajarai bahasa Inggris agar mampu berkompetisi dalam ajang internasional. Tidak hanya itu, bahkan kemasan makanan juga menggunakan bahasa Inggris sebagai petunjuk penggunaannya. Dalam kontek yang kedua, siswa dituntut untuk menguasai 4 skill dalam bahasa Inggris yakni kemampuan berbicara (speaking), kemampuan membaca (reading), kemampuan menyimak (listening) dan yang terahir kemampuan menulis (writing). Siswa akan dikatakan mahir berbahasa Inggris jika menguasai 4 skill tersebut. Tujuannya tidak lain adalah menciptakan siswa yang mampu dan dapat berkomunikasi baik dengan sejawat atau dengan orang lain menggunakan bahasa Inggris. 
Menjadi problem ketika siswa tidak semangat untuk mempelajari atau bahkan tidak suka untuk mempelajarinya.

Bahasa Inggris menjadi bahasa asing bagi pelajar Indonesia, oleh karenanya dalam mempelajari dan menguasainya tidak sedikit dari siswa menjumpai beberapa kendala dan bahkan tidak suka dan tidak tertarik untuk mempelajarinya. Beberapa alasan yang sering kita jumpai ketika siswa tidak tertarik untuk mempelajari bahasa Inggris. Pertama, karena bahasa Inggris sulit. Yang kedua karena metode guru ketika mengajar membosankan atau media yang digunakan tidak menarik serta konten yang disajikan dirasa tidak dibutuhkan atau tidak akrab ditelinga para pelajar. Dengan demikian, dibutuhkan solusi agar permasalahan dalam pembelejaran bahasa Inggris disa diatasi. Salah satunya dengan menvariasi metode dan teknik seperti menggunakan taknik bercerita.

Tehnik bercerita (story telling) merupakan salah satu tehnik yang disukai anak - anak dalam pembelajaran, khususnya dalam belajar Bahasa Inggris karena dengan teknik ini mereka bisa meningkatkan kemampuan menyimak (mendengar), menulis, sekaligus berbicara. Hal ini sejalan dengan Madyawati (2016) Bercerita adalah suatu kegiatan yang dilakukan seseorang secara lisan kepada orang lain dengan alat tentang apa yang harus disampaikan dalam bentuk pesan, informasi atau hanya sebuah dongeng yang dikemas dalam bentuk cerita yang dapat didengarkan dengan rasa menyenangkan. Nurgiyantoro (dalam Madyawati, 2016) berpendapat bahwa bercerita merupakan kegiatan berbahasa yang bersifat produktif. Artinya, dalam bercerita seseorang melibatkan pikiran, kesiapan mental, keberanian, perkataan yang jelas sehingga dapat dipahami oleh orang lain.(Pratiwi, 2016).

Menurut Kirsch cerita telah dianggap sebagai alat yang ampuh dan efektif dalam pembelajaran bahasa (Kirsch, 2016). Morgan and Rinvolucri (1983) dan Pesola (2008) juga menjelaskan bahwa cerita melibatkan pelajar, mengekspos mereka ke bahasa baru dan membantu mereka memperoleh bahasa target secara tidak sadar (Kirsch, 2016). Dalam artian ketika siswa mendengarkan cerita secara tidak langsung mereka sedang mempelajari bahasa. Menurut Sundmark dan Remi dalam (Mu'tashim \& Syafi'i, 2018) menjelaskan bahwa mendongeng memiliki sarana potensial untuk meningkatkan keterampilan bahasa anak.

Berikut ini adalahmanfaat mendongeng (story telling) menurut Wright (dalam Dolzhykova, 2014)

a. Cerita mampu memberikan konteks yang bermakna.

b. Cerita dapat memberikan pengulangan yang natural.

c. Anak-anak memiliki naluri lain dalam belajar bahasa

d. Keterampilan mendengarkan anak dapat dikembangakan.

Dalam menggunakan cerita berikut ada beberapa langkah yang bisa dilakukan menurut Tarigan (2008). 


\section{a. Menentukan topik cerita yang menarik}

Topik merupakan pokok pikiran atau pokok pembicaraan. Pokok pikiran dalam cerita harus menarik agar pendengar tertarik dan senang dalam mendengarkan cerita. Contoh topik cerita: pendidikan, sumber daya alam, kejujuran, persahabatan dan sebagainya.

\section{b. Menyusun kerangka cerita dengan mengumpulkan bahan-bahan}

Kerangka cerita merupakan rencana penulisan yang memuat garis-garis besar dari suatu cerita. Dalam menyusun kerangka cerita, harus mengumpulkan bahan-bahan seperti dari buku, majalah, koran, makalah dan sebagainya, untuk memudahkan dalam merangkai suatu cerita. Contoh kerangka cerita dengan topik persahabatan: 1) Ada dua orang bersahabat, 2) Dua orang sahabat berselisih paham, dan 3) Penyelesaian masalah \& kembali bersahabat.

\section{c. Mengembangkan kerangka cerita}

Kerangka cerita yang sudah dibuat kemudian dikembangkan sesuai dengan pokok-pokok cerita. Contoh pengembangan kerangka cerita ada 2 orang bersahabat sejak lama. Namanya Dina dan Ely. Mereka saling membantu satu sama lain. Saat Dina sedang mengalami kesulitan, Ely selalu membantu dan menghibur Dina. Begitupun sebaliknya, saat Ely sedang mengalami kesulitan, Dina selalu membantu \& menghibur Ely.

\section{d. Menyusun teks cerita}

Penyusunan teks cerita dilakukan dengan menggabungkan poin-poin dari kerangka cerita yang telah dikembangkan dengan memperhatikan keterkaitan antar poin. Contohnya yaitu menggabungkan pengembangan kerangka cerita poin 1 sd 3 yang telah dijelaskan di atas sehingga menjadi sebuah teks cerita yang baik.

\section{Metode}

Kegiatan ini diawali dengan pra pelaksanaan yang berupa survei lokasi dan wawancara dengan pihak lembaga dan murid sebagai gambaran untuk dijadikan acuan dalam menyusun rangkaian kegiatan. Adapun sasara kegiatan ini merupakan murid MTs. Miftahul Ulum gunung Tangis. Kegiatan ini dilaksanakan dalam bentuk mengajar di dilam kelas. Dalam kegiatan ini narasumber melaksanakan kegiatan pengajaran bahasa Inggris dengan menggunakan metode carita Legend of Madura. Model ini dipilih karena berdasarkan observasi awal sisiwa disana kurang bersemangat dalam belajar bahasa Inggris karena bagi meraka bahasa Inggris merupakan sata pelajaran yang sulit untuk dipelajari dan ditambah lagi kurang bervariasinya media dan metode yang dipilih oleh guru saat kegiatan belajar mengajar di dalam kelas.

Kegiatan pengabdian ini tidak hanya bertujuan untuk meningkatkan semangat siswa dan belajar bahasa inggis tetapi juga bertujuan untuk memberikan gambaran bagi guru bagaimana menerapkan metode dan menggunakan media pembelajaran bahasa Inggris di dalam kelas. 


\section{Hasil dan Pembahasan}

\section{a. Hasil Pelaksanaan Kegiatan}

Berikut ini adalah hasil kegiatan PKM yang dilaksanakan di MTs.Miftahul Ulum Gunung Tangis di desa Rek-kerrek Palengaan-Pamekasan.Para tim PKM memasuki ruangan yang didalamnya sudah berkumpil sekitar 30 siswi yang menjadi sasaran dari pengabdian kami, acara terlebih dahulu dirancang seperti seminar dengan susunan acara sebagai berikut: 1) Pembukaan. 2) Pengantar dari ketua Tim PKM. 3) Acara inti berupa pendampingan mengajar dengan menggunakan metode story telling dengan cara membagi siswa menjadi tiga kelompok. 4) Penutup.

Hasil dari pendampingan tersebut bisa dipaparkan berikut ini:

\section{1) Legend of Madura}

Legenda merupakan jenis cerita yang tergolong teks naratif, yaitu cerita tempat asal. Sedangkan legenda Madura merupakan cerita yang mengisahkan tentang legenda beberapa tempat di Madura seperti legenda Gunung Gegger di Bangkalan, legenda Api Tak Kunjung Padam di Jengkah Pamekasan dan lain sebagainya. Pada kegiatan ini tim PKM IAIN Madura sebanyak lima anggota sengaja mengambil tema ini agar lebih memudahkan siswa dalam belajar khususnya dalam pembelajaran Bahasa Inggris karena dengan metode story telling diharapkan mereka lebih antusias dalam kegiatan pembelajaran dan tujuan pembelajaran bisa tercapai minimal memenuhi kriteria ketuntasan minimal (KKM).

Adapun langkah - langkah pembelajaran dalam kegiatan pendampingan yang kami lakukan sebagai berikut:

a) Memberi salam.

b) Menyapa siswa sembari memotivasi para siswa akan mamfaat belajar Bahasa Inggris.

c) Memberi stimulus pada para siswa tentang apa itu legenda.

d) Menanyakan jenis legenda apa saja yang mereka ketahui.

e) Para siswa menyebutkan jenis dari legenda Madura yang mereka ketahui seperti: Api Tak Kunjung Padam, Joko Tole, Gunung Gegger bahkan desa Rek-kerrek yang kebanyakan menjadi domisili mereka.

f) Memberikan materi dengan bercerita sembari membacakan buku cerita tentang Legend of Madura yang sudah kami berikan kepada mereka masing - masing.

g) Memberikan feedback berupa penjelasan ulang tentang apa yang mereka baca merupakan bagian dari narrative textyang didalamnya terdapat poin - poin berikut ini:

h) Dari segi tenses menggunakan past tense dan dari segi generic structure bisa dilihat berikut ini:

1) Orientation (pengenalan text yang berupa tokoh,tempat dan waktu).

2) Complication (konflik atau permasalahan yang dihadapi si tokoh dalam cerita tersebut).

3) Resolution (akhir dari cerita tersebut atau jawaban dari masalah yang dihadapi si tokoh). 
i) Menanyakan kembali kepada para siswa untuk mengecek pemahaman mereka tentang legend serta secara bersamaan untuk mencari dan menentukan yang mana yang orientation, complication dan resolution.

j) Memberikan tugas berupa menuliskan kembali cerita madura dengan cara meresum apa yang mereka baca dari buku Legend of Madura tersebut. (foto bisa dilihat di lampiran).

\section{2) Metode Story Telling}

Tehnik bercerita ( story telling ) merupakan salah satu teknik yang disukai anak- anak dalam pembelajaran, khususnya dalam belajar Bahasa Inggris, karena dengan tehnik ini mereka bisa meningkatkan kemampuan menyimak (mendengar ), menulis, sekaligus berbicara, seperti yang telah dikemukakan oleh Madyawati (2016) Bercerita adalah suatu kegiatan yang dilakukan seseorang secara lisan kepada orang lain dengan alat tentang apa yang harus disampaikan dalam bentuk pesan, informasi atau hanya sebuah dongeng yang dikemas dalam bentuk cerita yang dapat didengarkan dengan rasa menyenangkan. Nurgiyantoro (dalam Madyawati, 2016: 162) berpendapat bahwa bercerita merupakan kegiatan berbahasa yang bersifat produktif. Artinya, dalam bercerita seseorang melibatkan pikiran, kesiapan mental, keberanian, perkataan yang jelas sehingga dapat dipahami oleh orang lain.

\section{3) Manfaat Metode Story Telling dengan menggunakan Legend of Madura}

Adapun beberapa manfaat yang bisa diperoleh dari metode story telling adalah sebagai berikut.

a) Siswa lebih antusias dalam belajar Bahsa Inggris.

b) Siswa lebih aktif dalam merespon pertanyaan guru.

c) Kemampuan berbicara bahasa Inggris mulai ada kemajuan.

d) Dapat menambah kosakata baru.

e) Meningkatkan motivasi belajar Bahasa Inggris mereka.

f) Dengan menggunakan buku bacaan berupa legend of Madura dapat meningkatkan pengetahuan mereka tentang cerita dan legenda yang ada di Madura.

g) Lebih aktif dalam menanyakan kosakata yang tidak mereka ketahui dalam menuliskan cerita tentang legenda madura tersebut.

\section{b. Pembahasan}

Kegiatan pendampingan Mengajar Melalui Metode Cerita Legend of Madura Di Madrasah Tsanawiyah Miftahul Ulum Gunung Tangis Desa Rekkerrek Kecamatan Palengaan yang dilakukan oleh tim PKM Prodi Tadris Bahasa Inggris Fakultas Tarbiyah IAIN Madura merupakan kegiatan yang dirasa sangat penting dan bermanfaat bagi pihak lembaga khususnya guru bahasa Inggris dan para murid karena kegiatan tersebut bisa memberikan variasi metode dan media mengajar yang bisa menghadirkan suasana belajar baru yang lebih menyenangkan. Kegiatan tersebut nampak sangat 
berpengaruh dalam meningkatkan motivasi murid dalam mengikuti kegiatan belajar mengajar khususnya mata pelajaran bahasa Inggris yang dikenal sulit di mata para murid. Hal ini bisa terlihat dari kondisi para siswa dalam mengikuti kegiatan pembelajaran saat pendampingan dan respons mereka saat diberikan pertanyaan yang berkenaan dengan materi yang sedang dibahas dan juga dalam mengerjakan latihan. Mereka antusias bertanya halhal yang tidak mereka pahami dan menjawab pertanyaan pendamping. Selain itu meraka lebih produktif dalam mempraktekkan keahlian berbahsan seperti bertanya munggunakan bahasa Inggris dan menulis ulang cerita. Hal ini sejalan dengan pendapat Nurgiyantoro (dalam Madyawati, 2016) berpendapat bahwa bercerita merupakan kegiatan berbahasa yang bersifat produktif.

Mengajar menggunakan teknik cerita sangat efektif untuk meningkatkan minat serta motivasi siswa belajar bahasa Inggris apalagi cerita yang disajikan adalah cerita yang mengandung sejarah asal muasal tempat dimana para murid tinggal yang dalam hal ini adalah Madura. Belajar bahasa Inggris melalui konten cerita rakyat juga memperkaya kosa kata siswa tanpa harus menghafal. Metode bercerita juga mampu meningkatkan antusias siswa dalam proses belajar mengajar. Ketuntasa Minimal (KKM).

\section{Kesimpulan}

Pendampingan Mengajar Melalui Metode Cerita Legend of Madura Di Madrasah Tsanawiyah Miftahul Ulum Gunung Tangis dengan variasi metode dan media yang menghadirkan suasan lebih baru yang lebih menarik dan menyenangkan membantu mengatasi permasalahan yang dihadapi guru dan murid dalam kegiatan pembelajaran bahasa Inggris serta mampu meningkatkatkan motivasi belajar para siswa dan menunjang tercapainya tujuan pembelajaran yang sudah ditetapkan. Para siswa lebih produktif dalam menunjukkan keahlian berbahsa Inggris mereka baik lewat keahlian berbicara maupun menulis.

\section{Rekomendasi}

Berangkat dari temuan saat pelaksanaan PKM, ada beberapa rekomendasi yang perlu dilakukan: 1) Perlunya untuk terus memberikan motivasi kepada siswa agar selalu bersemangat dalam belajar bahasa Inggris 2) Guru perlu terus memperbaharui metode dan media yang digunakan dalam pembelajaran bahasa Inggris seperti teknik bercerita 3) Perlu adanya pendampingan yang berkesinambungan melalui kegiatan Pengabdian Kepada Masyarakat.

\section{Daftar Pustaka}

Dariyo, A. (2004). Psikologi Perkembangan Remaja. Bogor: Ghalia Indonesia. 
Dolzhykova, O. (2014). Teaching English through Storytelling to Young Learners: Ukranian and Norwegian Experiences (Master Thesis). University of OSLO, Oslo.

Kirsch, C. (2016). Using Storytelling to Teach Vocabulary in Language Lessons: Does it Work? The Language Learning Journal, 44(1), 3351. doi: 10.1080/09571736.2012.733404

Maduwu, B. (2016). Pentingnya Pembelajaran Bahasa Inggris di Sekolah. Warta Dharmawangsa, 50(50). doi: 10.46576/wdw.v0i50.207

Madyawati, L. (2016). Strategi Pengembangan Bahasa Pada Anak. Jakarta: Prenada Media Group.

Morgan, J., \& Rinvolucri, M. (1983). Once Upon a Time: Using Stories in the Language Classroom. Cambridge: Cambridge University Press.

Mu'tashim, J. F., \& Syafi'i, A. (2018). The Power of Story Telling In Teaching Speaking. English Education: Journal of English Teaching and Research, 3(1), 1-7. doi: 10.29407/jetar.v3i1.11758

Pesola, C. (2008). Culture in the Elementary School Foreign Language Classroom. Foreign Language Annals, 24(4), 331-346. doi: 10.1111/j.1944-9720.1991.tb00478.x

Pratiwi, R. R. (2016). Penerapan Metode Storytelling untuk Meningkatkan Keterampilan Berbicara Siswa Kelas II SDN S4 BANDUNG. Jurnal Pendidikan Guru Sekolah Dasar, 1(1), 199-207. doi: 10.17509/jpgsd.v1i1.9074

Siregar, N. S. S. (2013). Persepsi Orang Tua terhadap Pentingnya Pendidikan bagi Anak. 17.

Tarigan, Henry Guntur. (2008). Berbicara Sebagai Suatu Keterampilan Berbahasa. Bandung: Angkasa. 